\title{
A fruição da obra de Francesca Woodman a partir de suas exposições
}

\author{
Renata Amado Sette Mosaner ${ }^{1}$ \\ DOI 10.20396/eha.vil4.3440
}

O trabalho da fotógrafa norte-americana Francesca Woodman (1958-1981) foi retomado por críticos significativos inicialmente em 1986, em um catálogo publicado por ocasião de sua primeira exposição póstuma. Amplamente conhecida no circuito fotográfico por seus autorretratos em preto-e-branco, Woodman produziu mais de oitocentas ampliações, alguns vídeos e livros de artista. Ao longo dos anos, a obra de Woodman foi exposta em uma extensa gama de instituições, de diferentes naturezas e configurações, relativas à dimensão, tempo de permanência e tantos outros fatores expositivos. Nessa grande variação, a obra dela transitou, por exemplo, tanto por um porão de uma livraria da Itália na década de 1970, como na espaçosa Tate Modern nos anos 2000. Em tal contexto, é possível indagar que a recepção e a fruição de uma obra de arte, em parte, também são produtos das escolhas e da maneira em que ela é apresentada ao público? Em outras palavras, é plausível inferir que as diversas circunstâncias expositivas proporcionaram diferentes relações fruitivas com o público? Embora não seja viável mensurar e definir limites claros a essa avaliação, este artigo pretende explorar como a dimensão coletiva da recepção das obras, no tocante às estruturas expositivas e a determinadas mudanças sócio-culturais, pode ter sido alterada ao longo das últimas décadas, no caso específico de Francesca Woodman.

Se a fruição de uma obra de arte é inerentemente vinculada a um contexto artístico mais amplo, é fundamental rememorar de forma breve que nas últimas quatro décadas o sistema de arte se transfigurou em uma pluralidade sem precedentes. As suas categorias clássicas, como a pintura e a escultura, foram desmanteladas em uma gama de novas formas, materiais e práticas, como a Pop Art, a performance, a land art, a arte conceitual, o minimalismo, entre outras. Na década de 1970, na qual a fotógrafa Francesca Woodman (1958-1981) atuou, essa variedade é meramente ponto de partida para uma fragmentação ainda maior, tomada por uma profusão de artistas e obras díspares. Para Rosalind Krauss (1977), é como se esses artistas, inclassificáveis enquanto conjunto, tivessem como base uma liberdade pessoal de criação, que antes era impedida pelos estilos já pré-

1 Mestranda do Programa de Pós-Craduação Interunidades em Estética e História da Arte da Universidade de São Paulo. O presente trabalho foi realizado com apoio da Coordenação de Aperfeiçoamento de Pessoal de Nível Superior - Brasil (CAPES) - Código de Financiamento 001. 
delineados. Nesse contexto, nota-se também significativas mudanças relativas à fruição do público à arte contemporânea, especialmente nos museus.

A partir da década de 1980, tornou-se recorrente o termo "cultura dos museus" para designar um processo de intensas modificações, principalmente nos aspectos político e administrativo, que se instauraram em alguns museus europeus e norte-americanos. É convencionado pela crítica que este fenômeno tem o seu primórdio com a inauguração do Beaubourg (Centro Ceorges Pompidou), em Paris, em 1977. Certamente essas alterações estão atreladas a uma equação complexa, que compreende aspectos como: a valorização da obra de arte como mercadoria; a estetização dos museus na década de 1980; o ingresso da iniciativa privada como patrocinadores e a introdução do mundo cotidiano ao ambiente até então circunscrito à alta cultura (ARANTES, 1993)². Como consequência visível deste processo, tais espaços museológicos têm se assemelhado a shopping centers e parques temáticos, de forma que a obra de arte é escancarada como bem de consumo, em meio a essa cultura da aceleração. Segundo os dados reunidos por Gilles Lipovetsky e Jean Serroy (2014), a cada cinco anos, o número de museus no mundo aumenta em 10\%. Na França, por exemplo, a quantidade de galerias dobrou durante a década de 1980. Nos EUA, havia 1200 museus nos anos 1920 e no início da década de 1980, este número subiu para 8000. Esses dados demonstram o que Lipovetsky denomina como "inflação estética", que caracteriza o "capitalismo artístico". Para o autor, nessa fase do capitalismo, a atividade estética ocupa um lugar primordial:

A arte aparece cada vez mais como uma mercadoria entre outras, como um tipo de investimento do qual se espera uma alta rentabilidade. A idade romântica da arte deu lugar a um mundo no qual o preço das obras é mais importante e mediatizado do que o valor estético: agora são o preço comercial e o mercado internacional que consagram o artista e a obra de arte. ${ }^{3}$

O receptor ou o "filho do capitalismo artístico", como querem Lipovetsky e Serroy (2016), não frequenta mais o museu pelo "antigo amor à arte", como afirma Otília Arantes (1993), mas seduzido pelas copiosas atrações, como os cafés, livrarias, restaurantes, lojinhas e, substancialmente, a própria arquitetura. Com o erguimento de edifícios espetaculares, assinados por arquitetos famosos, as construções se tornam atração, competindo até com o que há em seu interior. As bienais, feiras de arte internacional e salões igualmente se multiplicaram: "[as] megaexposições, como as Bienais

\footnotetext{
2 ARANTES, O. B. F. O lugar da arquitetura depois dos modernos. São Paulo: Edusp: Studio Nobel, 1993.

3 LIPOVETSKY, G. e SERROY, J. O capitalismo estético na era da globalização. Lisboa: Edições 70, 2014, p. 51.
} 
de arte espalhadas pelo mundo, são gerenciadas e anunciadas como grandes espetáculos do mundo mass-midiático. São eventos de grandes proporções"4.

Tal conjuntura atravessa e é igualmente atravessada pelo período e pelas circunstâncias em que Francesca Woodman começou a ter a sua obra exposta com maior frequência. Ainda em vida, Woodman participou de algumas exposições coletivas e ao menos de três pequenas exposições individuais ${ }^{5}$. Somente em 1986, cinco anos após o seu suicídio, o trabalho ganha uma primeira grande exposição individual: Francesca Woodman, Photographic Work, organizada por Ann Cabhart e Rosalind Krauss. Até o início da década de 1990, o trabalho de Woodman permaneceu circunscrito a cidades dos Estados-Unidos. É interessante notar que do início de suas exposições, com a fotógrafa ainda em vida (1976), passando por essa primeira retrospectiva póstuma (1986), e incluindo uma exposição de 1989, praticamente todas as exposições ocorreram em museus universitários ou galerias diretamente ligadas a este tipo de instituição. As singularidades do museu universitário residem exatamente na raiz acadêmica de sua origem: “(...) eles fazem parte de uma rede de ensino e pesquisa que os coloca na linha de frente para novos desenvolvimentos na maneira como objetos

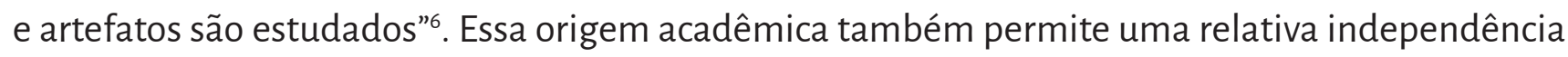
do mercado de arte (COSTA, 2008). Mas certamente podem servir de vitrine para um mercado mais agitado, como ocorreu nitidamente no caso de Woodman. Em 1992, a obra não apenas se desloca para alguns países europeus ${ }^{7}$, como também sai dos museus universitários para adentrar galerias de arte. Este movimento anuncia uma passagem emblemática da recepção da obra de Woodman, na qual ela sai de uma instituição fundamentalmente ligada às atividades acadêmicas para se lançar a outro tipo de instituição, cujas maiores preocupações são o acúmulo do capital e o mercado de arte.

Entretanto, apenas em 1998 o circuito da obra de Woodman aparenta se comunicar em maior intensidade com características mais evidentes da "cultura do museu". Se até 1997, Woodman tinha a sua obra exposta individualmente com uma frequência de uma a duas vezes por ano, em 1998 esse número sobe para quatro vezes. Não é apenas pelo aumento da quantidade de exposições que tal ano se faz ímpar. Algumas circunstâncias dessas exposições são essenciais para refletirmos a recepção expositiva da obra neste período. As exibições desse ano, incluindo um tour promovido pela

\footnotetext{
4 FABBRINI, R. A fruição nos novos museus. Especiaria: Cadernos de Ciências Humanas, Ilhéus, v. 11, n. 19, p. 245-268, jan./jun. 2008, p. 245.

5 As exposições foram na Addison Gallery of American Art em 1976; na Rhode Island School of Design e na Libreria Maldoror, ambas em 1978.

6 KIM, H. Crossing Cultures: Redefining a University Museum. RES: Anthropology and Aesthetics, n. 52, p. 44-50, 2007, p. 45, tradução nossa.

7 Entre 1992 e 1993, a exposição Francesca Woodman, Photographic Arbeiten, circulou pela Suíça, Suécia, Alemanha, Finlândia e Noruega.
} 
Fondation Cartier pour l'art contemporain, circularam majoritariamente pela Europa, em novos países como França, Holanda, Espanha, Portugal, Itália e Irlanda. Ainda neste tour, que durou quatro anos, a obra foi exibida no grande festival PhotoEspaña. A obra também foi integrada no Rencontres Internationales de la Photographie de Arles, em sua primeira edição. Dessa forma, as exposições não se restringem mais a museus universitários e tampouco a galerias, e sim atingem uma quantidade e uma diversidade de espaços expositivos inéditas: a obra é exposta em duas galerias, um museu, um festival específico de fotografia e uma fundação de arte contemporânea. Na Holanda, por exemplo, o trabalho ficou exposto no Kunsthal de Rotterdam, local que claramente é coerente a essa quebra de padrões expositivo-administrativo. Em destaque no site dessa instituição, afirma-se que o museu "(...) é um dos ícones da arquitetura moderna e é visitado todos os anos por um grande número de amantes da arquitetura de todo o mundo." O edifício foi elaborado pelo "arquiteto mundialmente conhecido Rem Koolhaas" e o projeto arquitetônico foi feito por "Fuminori Hoshino da firma de arquitetos de Rotterdam, OMA (Office for Metropolitan Architecture)" ${ }^{8}$. Ou seja, os elementos envolvidos neste complexo, sejam pessoas ou objetos, são exaltados como uma grife, que por sua vez repercutem na imagem espetacular da instituição. O capitalismo focado na produção é substituído por um capitalismo que opera na base da sedução: "O trabalho imediatamente atraiu ampla atenção internacional por características como o uso inovador do material, a posição da entrada e as rampas íngremes (...). O robusto edifício abriga sete espaços para exposições, um auditório característico e um café com um ambiente próprio." . Essa descrição institucional parece ir em direção à reflexão de Lipovetsky e Serroy a respeito do capitalismo artístico:

O capitalismo tornou-se artístico no sentido em que está sistematicamente envolvido em operações que, ao fazer apelo aos estilos, às imagens, ao divertimento, mobilizam os afetos, os prazeres estéticos, lúdicos e sensíveis dos consumidores. ${ }^{10}$

Essa lógica se repete no caso do edifício da Fondation Cartier, que proporciona, inclusive, visitas guiadas especificamente voltadas à arquitetura e mobiliário, o qual também foi desenvolvido exclusivamente para o prédio. Também é imprescindível memorar que essa fundação pertence a uma das maiores joal herias do mundo, o que reafirma o peso da iniciativa privada ao funcionamento da cultura dos museus. Nestas circunstâncias cabe o questionamento de Lipovetsky: será que o

\footnotetext{
8 KUNSTHAL ROTTERDAM, tradução nossa. Disponível em: https://www.kunsthal.nl/en/about-kunsthal/building. Acesso em: 23 jul. 2019.

9 Ibid., tradução nossa.

10 LIPOVETSKY, G. e SERROY, J. Op. cit., p. 47.
} 
capitalismo não funciona também como um "empresário de arte" e um "motor estético"?"1 As exposições de Woodman no Encontro de Arles e no festival PhotoEspaña também são pontos de contato com esse sistema, na medida em que entram nessa lógica da megaexposição e da "explosão dos lugares da arte".

A obra de Woodman retornou à Itália e especificamente à Libreria Maldoror ${ }^{12}$ algumas vezes, mas ela somente recebe uma enorme apresentação neste país em 2000, no Palazzo delle Esposizioni, em Roma. Em 2006, tem um pico de 5 exposições. Nos anos seguintes, a obra de Woodman passa por museus renomados: a Tate Modern (2007), a Scottish National Gallery of Modern Art (2009), o San Francisco Museum of Modern Art (2011) e o Guggenheim Museum de Nova York (2012). A exposição no Museum ofModern Art de São Francisco foi uma espécie de reestréia do trabalho de Woodman nos Estados-Unidos, depois de ter sido exposto em várias regiões européias: "a principal exposição exibida no Museu de Arte Moderna de São Francisco (2011-2012) e no Museu Solomon R. Guggenheim em Nova York (2012) evidenciou a crescente apreciação de sua arte nos Estados Unidos”³. Em um circuito mais restrito, tem a sua obra exposta em instituições ligadas à fotografia, como o Finnish Museum of Photography (2017), a Fondation Henri Cartier-Bresson (2016) e o Foam Museum (2015), em Amsterdam. A dimensão e as condições das exposições individuais da obra de Woodman variaram bastante ao longo deste período, mas raros foram os anos em que a obra não foi exposta nenhuma vez. Woodman também participou de diversas exposições coletivas. De forma vertiginosa, as exposições coletivas aumentaram em dez vezes entre as décadas de 1980 e 2000.

O trabalho de Woodman é mergulhado em "zonas de indeterminação", termo de Jacques Rancière ${ }^{14}$. Suas imagens são marcadas por cenários em decadência, fragmentações, elementos nebulosos e obscuridades inquietantes. "A maior parte do tempo, uma imagem nos interessa porque indica alguma coisa que não está na imagem: pelo que nos deixa adivinhar, ou pelo que continua a ocultar. Somos muito mais os detetives do sensível que os seus voyeurs"15. Também poderíamos afirmar que as fotografias de Woodman são o que Jacques Rancière configura como uma "imagem pensativa". Esta se caracteriza por criar "(...) um efeito sobre quem a vê sem que este a ligue a um objeto determinado"16. É um pensamento que flana entre a atividade e a passividade, sem uma dis-

\footnotetext{
11 Ibid., p. 43.

12 Galeria e livraria que Francesca visitava assiduamente durante a sua residência em Roma e que foi relevante em sua vida e obra.

13 SCHOR, G.; BRONFEN, E. (org.). Francesca Woodman: Works from the Sammlung Verbund. Vienna: Sammlung Verbund, 2014, p. 8, tradução nossa.

14 RANCIÈRE, J. O espectador emancipado. Trad. Ivone C. Benedetti. São Paulo: Martins Fontes, 2012.

15 LEBRUN, G. A mutação da obra de arte. In:

16 RANCIÈRE, J. Op. cit., p. 103 A filosofia e sua história. São Paulo: Cosac Naify, 2006, p. 336.
} 
tinção apurada desses limites. Especificamente na fotografia, o filósofo caracteriza essa "pensatividade" como "(...) efeito da circulação entre o motivo, o fotógrafo e nós [o público], do intencional e do não intencional, do sabido e do não sabido, do expresso e do não expresso, do presente e do passado". ${ }^{17}$ Mas no contexto apresentado, em que o flâneur do museu se transformou em um corredor de maratona, como ironiza Andreas Huyssen (1997), ainda é possível atribuir tal caráter pensativo à obra de Woodman?

Inevitavelmente, a fruição de uma obra depende de abundantes variáveis e não é um artigo mensurável. Ela sempre será, em alguma instância, uma percepção subjetivada da obra. É relativamente recente a concepção de que o público também é incumbido pela elaboração de significado da obra de arte, o que desponta no fim da década de 1960 com a Estética da Recepção de Robert Hans Jauss. Em consonância a essa abordagem, Umberto Eco também atribui ao fruidor uma porção da tarefa de formular os sentidos da obra. Para ele, uma obra se faz "aberta" na medida em que é "(...) uma mensagem fundamentalmente ambígua, uma pluralidade de significados que convivem num só significante"18. Entretanto, o que estamos colocando é que a fruição parece ser um processo que além de envolver toda essa dimensão subjetiva, também está diante de uma cultura intensamente acelerada, da qual é inviável ficar incólume. A "pensatividade" da obra de Woodman não é eliminada, a princípio. Entretanto, as circunstâncias da recepção da obra podem não favorecer uma fruição mais demorada. A experiência de se implicar a uma obra de arte e se deixar permear pela mesma, foi substituída em grande parte, por uma relação simplificada de pura checagem da imagem. Uma vez confirmada e registrada a sua existência (diversas vezes através de selfies), é hora de passar para a próxima obra. Esse ritmo estorva ou talvez liquide qualquer possibilidade de recolhimento do fruidor. Para Lipovetsky e Serroy:

Hoje, é necessário colocar duas formas ou duas versões da vida estética muito diferentes: uma dominada pela submissão às normas aceleradas e ativistas do consumismo, a outra pelo ideal de uma existência capaz de escapar às rotinas da vida e das compras, de suspender a 'ditadura' do tempo apressado, de provar o sabor do mundo demorando o tempo da descoberta. ${ }^{19}$

Nesse sentido, esses autores parecem ver abertura para ao menos dois modos de fruição estética, incluindo tal fruição mais demorada. Para outros críticos, esse recolhimento necessário já

\footnotetext{
17 Ibid., p. 110.

18 ECO, U. Obra Aberta: formas e indeterminação nas poéticas contemporâneas. 10ª ed. São Paulo: Editora Perspectiva, 2015, p. 29.

19 LIPOVETSKY, G. e SERROY, J. Op. cit., p. 153).
} 
não pertence à sociedade vigente, porque vivemos em uma cultura que não convoca mais "à contemplação e ao recolhimento"20 e que considerá-los na esfera dos museus seria um "anacronismo inviável"21.

Portanto, retomando o nosso questionamento inicial, notamos que irrefutavelmente a recepção da obra de Woodman está intrincada não apenas aos dispositivos de exibição, mas a aspectos muito mais amplos da cultura globalizada. Ao debater a fruição da obra de Francesca Woodman dentro dos museus, estamos incitando, de fato, um entrelaçado de outras perguntas, relacionadas a "(...) uma notável mudança nas formações de sensibilidade, das práticas e de discurso que torna um conjunto pós-moderno de posições, experiências e propostas distinguível do que marcava um período precedente." ${ }^{22}$. Sem descartar o universo subjetivo que uma obra pode oferecer ao público, nota-se que a recepção de uma obra também é filtrada por um poderoso teor, balizado por valores e aspectos coletivos. Cabe-nos refletir a abrangência dessa temática, reconhecendo que, não estamos apenas analisando o caso de Francesca Woodman, mas, mais profundamente, estamos discutindo algumas consequências da aproximação intensa entre o sistema econômico, a cultura e a arte. 


\section{Referências}

ARANTES, O. B. F. O lugar da arquitetura depois dos modernos. São Paulo: Edusp: Studio Nobel, 1993.

COSTA, H. Da fotografia como arte à arte como fotografia: a experiência do Museu de Arte Contemporânea da USP na década de 1970. An. Mus. Paul., São Paulo, v. 16, n. 2, p.131-173, Dez. 2008. Disponível em: <https://bit.ly/2NixGaF>. Acesso em: 21 mai 2018.

ECO, U. Obra Aberta: formas e indeterminação nas poéticas contemporâneas. 10 ${ }^{a}$ ed. São Paulo: Editora Perspectiva, 2015.

FABBRINI, R. A fruição nos novos museus. Especiaria: Cadernos de Ciências Humanas, Ilhéus, v. 11, n. 19, p. 245-268, jan./jun. 2008.

HUYSSEN, A. Mapeando o pós-moderno, In: HOLLANDA, Heloísa Buarque. Pós-Modernismo e Política, Rio de Janeiro: Rocco, 1991.

JERINIC, K. (org). Biography. In: SCHOR, G.; BRONFEN, E. (org.). Francesca Woodman: Works from the Sammlung Verbund. Vienna: Sammlung Verbund, 2014.

KELLER, C. Francesca Woodman. São Francisco, CA: San Francisco Museum of Modern Art, 2011.

KIM, H. Crossing Cultures: Redefining a University Museum. RES: Anthropology and Aesthetics, n. 52, p. 44-50, 2007. Disponível em:< http://www.jstor.org/stable/20167738>. Acesso em: 18 set. 2019.

KRAUSS, R. Notes on the Index: Seventies Art in America. October, V. 3, pp. 68-81, Primavera 1977. Disponível em: <http://www.jstor.org/stable/778437>. Acesso em: 13 Nov 2017.

LEBRUN, GÉRARD. A mutação da obra de arte. In: A filosofia e sua história. São Paulo: Cosac Naify, 2006.

LIPOVETSKY, G. e SERROY, J. O capitalismo estético na era da globalização. Lisboa: Edições 70, 2014.

A estetização do mundo: viver na era do capitalismo artista. Trad. Eduardo Brandão. São Paulo: Companhia das Letras, 2016.

RANCIÈRE, J. O espectador emancipado. Trad. Ivone C. Benedetti. São Paulo: Martins Fontes, 2012.

SCHOR, G. Introductory Remarks and Acknowledgments. In: SCHOR, G.; BRONFEN, E. (org.). Francesca Woodman: Works from the Sammlung Verbund. Vienna: Sammlung Verbund, 2014.

\section{Referências on-line}

KUNSTHAL ROTTERDAM. The Building. Disponível em: https://www.kunsthal.nl/en/about-kunsthal/building/ Acesso em: 15 set. 2019

FONDATION CARTIER POUR L'ART CONTEMPORAIN. The building. Disponível em: https://www.fondationcartier. com/en/building Acesso em: 15 set. 2019.

VICTORIA MIRO. Francesca Woodman CV. Disponível em: https://www.victoria-miro.com/usr/library/documents/ main/7/cv-woodman.pdf. Acesso em: 24 set. 2019. 